\title{
Prognosticators and Management of Oral Tongue Squamous Cell Carcinoma
}

\author{
Ahmed Hamadnallah ${ }^{1}$, Ammar Alhidai ${ }^{2}$, Ali A Elobeid ${ }^{3}$ and Yousif I Eltohami** \\ ${ }^{1,2,3}$ Dental Students, University of Khartoum, Sudan
}

${ }^{4}$ Department of Oral and Maxillofacial Surgery, University of Khartoum, Sudan

Submission: January 25, 2020; Published: February 08, 2021

*Corresponding author: Yousif I Eltohami, Department of Oral and Maxillofacial Surgery, Faculty of Dentistry, University of Khartoum, Sudan

\section{Abstract}

Background: Worldwide, oral cancer is ranked as the fifth most fatal cancer. It has different clinical presentations, specifically, patients with tongue cancer typically present with a sore or a lump. The treatment depends on the stage, with single modality treatment being the most used for stage I and II tumors, and combined treatment being used most of advanced stages.

Methodology: This is a retrospective study done in Khartoum Dental Teaching Hospital on patients diagnosed with tongue squamous cell carcinoma from 2011 to 2019.

Results: A total of 69 patients were included in this study, $58 \%$ of the patients were females and $42 \%$ were males. The majority of the patients were stage IV (66.7\%), followed by stage III (18.8\%), and only $(7.2 \%)$ were at stage II. Most of the patients received surgical treatment $(52.2 \%)$ with (15.9\%) having adjuvant therapy and (18.8\%) had both, segmental resection was the most common surgical resection in this study followed by soft tissue and marginal resection $(43.5 \%, 15.9 \%$, and $2.9 \%$ respectively). The surgical margins were negative in (37.7\%), positive in $(11.5 \%)$ and close in $(1.4 \%)$. There was a perineural invasion in $(21.7 \%)$ and was absent in $(65.2 \%)$, microscopic depth of invasion was >or equal to $4 \mathrm{~mm}$ in $(52.2 \%)$, $>4 \mathrm{~mm}$ in $(1.4 \%)$ and $<4 \mathrm{~mm}$ in $(10.1 \%)$. The overall survival rate for the patients in this study was $(45 \%)$.

Conclusion: The current study showed that the most common site of this cancer was the lateral part of the tongue. Also, an increase in the incidence of tongue cancer among adults of 40 to 60 years old was found. Most of the patients in this study were at a late stage. Ulcerative swelling was the most common clinical feature. Moreover, surgical treatment was the most common treatment done to the patients and the overall survival rate of the patients was $45 \%$.

Keywords: Tongue; Squamous cell carcinoma; Staging; Treatment; Outcomes

\section{Introduction}

Oral cancer is the fifth most fatal cancer worldwide [1], In developed countries, the most common site of oral cancer is the tongue whereas in Sudan the gingivo-buccal sulcus is more predominant due to an increase in smokeless tobacco usage [1]. The most dominant risk factors of all head and neck cancers including the tongue are chewing tobacco and using snuff [2-6]. The most common clinical presentation in patients with tongue cancer is a sore or lump, it can also be presented as an indurated ulcer with raised edges or as an exophytic growth. A 2 centimeters, small growth with no spreading to the lymph nodes is considered a Stage I tumor, if its dimensions are between 2-4 centimeters without spreading to the lymph nodes it's a Stage II tumor, a Stage III tumor is larger than 4 centimeters with no spread to the regional lymph nodes. If the tumor spreads to nearby tissues, lymph nodes or any other body part it is considered a Stage IV tumor regardless of its size $[7,8]$. In stage I and II tumors, single modality treatment is preferred (surgery or radiotherapy), for advanced stages (Stage III and IV tumors) combined treatment has proven to be more effective (surgery + radiology/ Chemoradiotherapy) [9]. The current study aimed to determine the presentations, histopathologic predictors, and clinical outcomes of tongue squamous cell carcinoma at Khartoum Teaching Dental Hospital.

\section{Materials and Methods}

The authors retrospectively identified all patients diagnosed with tongue squamous cell carcinoma from 2011 to 2019 at Khartoum Teaching Dental Hospital. Inclusion criteria were 
Sudanese patients diagnosed with squamous cell carcinoma of the tongue. Patient's tumor characteristics, demography, and treatment were taken from relevant medical records with the approval of the University of Khartoum Faculty of Dentistry, Ethical Committee Review Board, and the research unit in Khartoum Teaching Dental Hospital. Data were collected in data collection sheets and analyzed using SPSS version 22 and the results were presented in tables and graphs.

\section{Results}

A total of 69 patients were included in the current study. The most common age group was from 41 to 60 years followed by $>60$ ( $42 \%$ and $31.9 \%$ respectively), $58 \%$ of the patients were females and $42 \%$ were males. The most common site of this cancer was the lateral part of the tongue $(87 \%)$ followed by the anterior part $(10 \%)$ and finally the posterior part with (3\%) (Figure 1). Sixty-six percent of the patients had a tumor that wasn't fixed to the floor of the mouth while $(33.3 \%)$ of the patients had a tumor that was fixed. Patients who underwent partial glossectomy in the current study were (63\%) followed by hemiglossectomy (29\%) and finally subtotal glossectomy with a percentage of (8\%) (Figure 2), (Table 1). Sixty-six percent of the patients presented at stage IV followed by stage III (18.8\%) and only (7.2\%) were at stage II. Most of the patients received surgical treatment (52.2\%) with (15.9\%) having adjuvant therapy and (18.8\%) had both, $(34.8 \%)$ of the patients had mandibulotomy while (29\%) didn't (Figure 3), (Table 2).

Figure 1: Site of cancer.

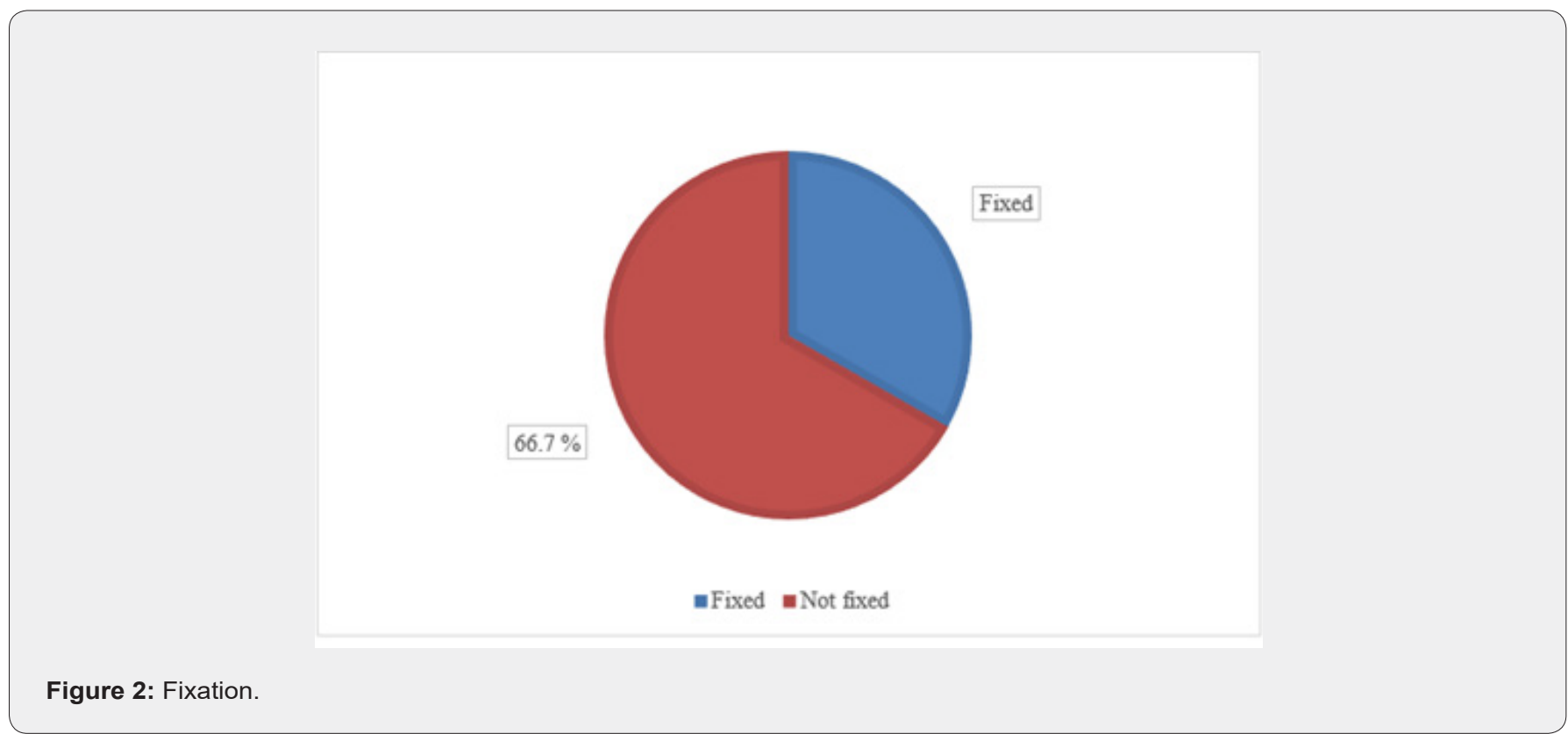




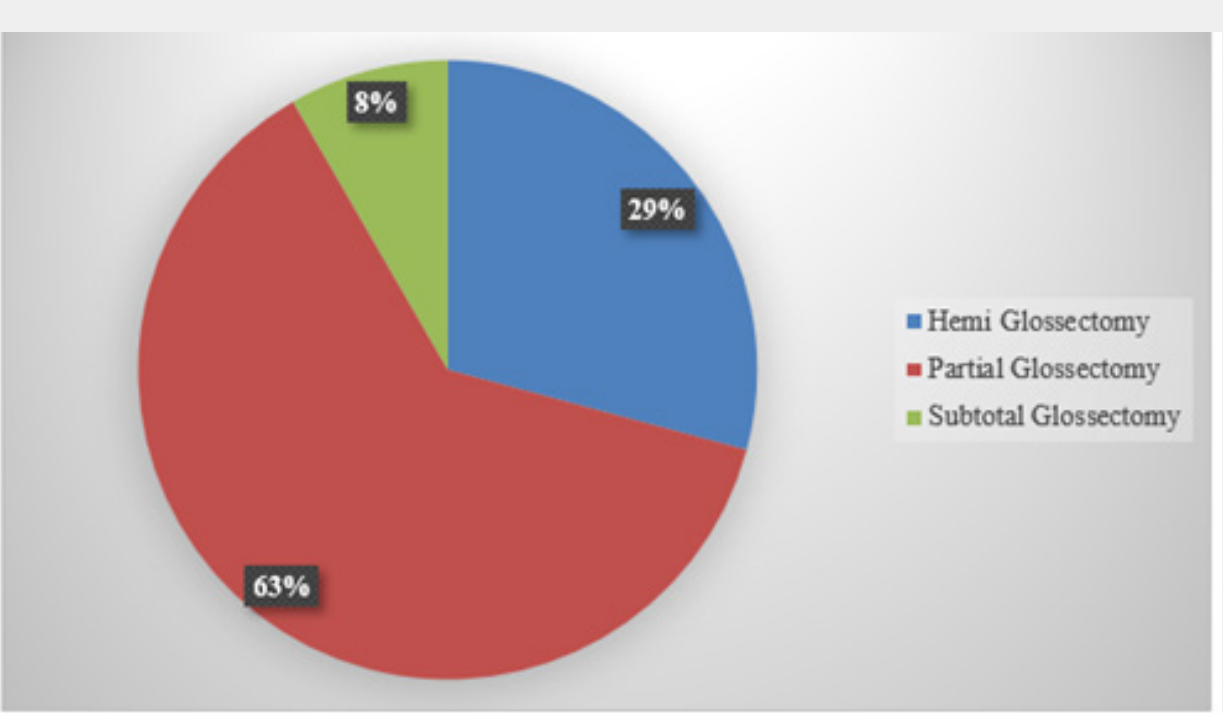

Figure 3: Type of surgery.

Table 1: Type of treatment.

\begin{tabular}{|c|c|c|}
\hline & Frequency & Valid Percent \\
\hline Valid & 7 & 10.1 \\
\hline Adjuvant & 11 & 15.9 \\
\hline both & 13 & 18.8 \\
\hline Surgical & 36 & 52.2 \\
\hline Total & 69 & 100 \\
\hline
\end{tabular}

Segmental resection was the most common surgical resection in this study followed by soft tissue and marginal resection (43.5\%, $15.9 \%$, and $2.9 \%$ respectively). The surgical margins were negative in (37.7\%), positive in (11.5\%), and close in $(1.4 \%)$. There was a perineural invasion in $(21.7 \%)$ and was absent in (65.2\%), microscopic depth of invasion was >or equal to $4 \mathrm{~mm}$ in $(52.2 \%)$, $>4 \mathrm{~mm}$ in $(1.4 \%)$ and $<4 \mathrm{~mm}$ in $(10.1 \%)$ (Table $3-6)$.
Table 2: Mandibulotomy.

\begin{tabular}{|c|c|c|}
\hline & Frequency & Valid Percent \\
\hline Valid & 18 & 26.1 \\
\hline No & 24 & 29 \\
\hline Yes & 27 & 34.8 \\
\hline Total & 69 & 100 \\
\hline
\end{tabular}

Local recurrence occurred in (4.3\%), locoregional in $(1.4 \%)$ and (44.9\%) did not experience recurrence. The majority did not receive treatment for the recurrence $(91.3 \%)$, while $(1.4 \%$ and $4.3 \%$ ) got treated with radiotherapy and surgery respectively, the overall survival rate for the patients in this study was (45\%) (Table 7), (Figure 4).

Figure 4: Percentage of dead and alive patients. 
Table 3: Type of surgical resection.

\begin{tabular}{|c|c|c|}
\hline & Frequency & Valid Percent \\
\hline Valid Non & 18 & 26.1 \\
\hline Marginal & 2 & 2.9 \\
\hline Missing & 8 & 11.6 \\
\hline Segmental & 30 & 43.5 \\
\hline Soft tissue & 11 & 15.9 \\
\hline Total & 69 & 100 \\
\hline
\end{tabular}

Table 4: Surgical margins.

\begin{tabular}{|c|c|c|}
\hline & Frequency & Valid Percent \\
\hline Valid & 16 & 23.2 \\
\hline.. & 2 & 2.9 \\
\hline Close & 1 & 1.4 \\
\hline Negative & 26 & 37.7 \\
\hline positive & 8 & 11.5 \\
\hline Total & 69 & 100 \\
\hline
\end{tabular}

Table 5: Perinural invasion.

\begin{tabular}{|c|c|c|}
\hline & Frequency & Valid Percent \\
\hline Valid & 7 & 10.1 \\
\hline No & 45 & 65.2 \\
\hline Yes & 15 & 21.7 \\
\hline Total & 69 & 100 \\
\hline
\end{tabular}

Table 6: Microscopic depth of invasion.

\begin{tabular}{|c|c|c|}
\hline & Frequency & Valid Percent \\
\hline Valid & 7 & 10.1 \\
\hline$<4 \mathrm{~mm}$ & 7 & 10.1 \\
\hline$<4 \mathrm{~mm}$ & 1 & 1.4 \\
\hline$>4 \mathrm{~mm}$ & 1 & 1.4 \\
\hline$\geq 4 \mathrm{~mm}$ & 36 & 52.2 \\
\hline missing & 17 & 24.6 \\
\hline Total & 69 & 100 \\
\hline
\end{tabular}

Table 7: Site of recurrence.

\begin{tabular}{|c|c|c|}
\hline & Frequency & Valid Percent \\
\hline Valid & 2 & 2.9 \\
\hline$\cdot$ & 32 & 46.4 \\
\hline local & 3 & 4.3 \\
\hline locoregional & 1 & 1.4 \\
\hline no & 31 & 44.9 \\
\hline Total & 69 & 100 \\
\hline
\end{tabular}

\section{Discussion}

This is a retrospective study carried out on 69 Sudanese oral tongue squamous cell carcinoma (OTSCC) patients at Khartoum
Teaching Dental Hospital to assess the staging and treatment outcomes of OTSCC. The tongue is the most common site of oral cancer in the developed countries [1], it affects both males and females with a male predominance. It has many risk factors including chewing tobacco, human papillomavirus, and others. Patients usually present with upper aero-digestive tract symptoms but most importantly tongue pain and a non-healing ulcer on the tongue. Regarding patients characteristics that were made about OTSCC, most of the patients were between the ages 40-60 years (42\%), (31.9\%) were above the age of 60 and only $(26,1 \%)$ were less than 40 years, in similar findings with Masaru Tateda et al. results in which $77 \%$ of the patients were $<40$ years and $23 \%$ were $>40$ years [10].

About the gender of the patients, the results showed that females had a higher percentage than males (58\% and $42 \%$ respectively ), in agreement to Najeeb TA et al. which had closely similar results in which $53.7 \%$ of the patients were females and $47.3 \%$ were males [11], on the other hand, Masaru Tateda et al. results showed male predominance in which $64 \%$ of the patients were males and $36 \%$ were females, the difference in the results is probably because Masaru Tateda et al. investigated only 39 patients while the authors investigated 69 patients [10]. Also, Werner Garavello et al. results were different from the authors' as it showed male predominance in which $67 \%$ of the patients were males and 33\% were females [12]. Moreover, the marital status, $82 \%$ of the patients were married, (13\%) were single and only $1.4 \%$ were divorced, in closely similar findings to Wei Sun et al. results which suggested that $58.5 \%$ of patients were married and $14.1 \%$ were divorced [13]. Subsequently, the occupation, (53\%) of the patients were housewives, $(29 \%)$ were freelancers, and only (1\%) were nurses, no previous studies discussed this parameter.

In concern to the smoking status of the patients, $(1.4 \%)$ were shisha smokers, (7.2\%) were cigarette smokers and (91.3\%) were non-smokers. In contrast, B F Adeyemi et al. results showed that $(80 \%)$ of the patients involved in the study were exposed to tobacco smoking [14]. Also, G Bachar et al. found that (60.1\%) of the patients in his study were exposed to tobacco smoking [15]. Regarding the clinical presentation of the cancer in this study, ulcerative swelling was the most common clinical feature (18.8\%), (17.4\%) presented with pain and endophytic/pain, swelling/pain, endophytic/swelling/pain, and numbness all shared the same percentage (1.4\%) [16]. In contrast, Nootan Kumar Shukla found in his study that the most common clinical presentation was ulcer (45.1\%) followed by pain and neck swelling (5.6\%) [17]. About the site of this cancer, the most common site was the lateral part (87\%), (10.1\%) for the anterior and the least common was the posterior part (3\%), in similar findings to Nootan Kumar Shukla et al. results that showed that the most commonly involved site was the lateral part of the tongue (88.7\%) [17]. About the fixation of the tumor $(66.7 \%)$ of the patients in this study had a tumor that was not fixed to the floor of the mouth and $(33.3 \%)$ of them had a tumor that was fixed. No previous studies have discussed this parameter. Regarding induration, the current study showed that 
they were present in $(50.7 \%)$ of patients while were absent in (49.3\%), no previous studies discussed this parameter. Regarding the bone involvement of the tumor, (99\%) of the patients in this study did not have bone involvement while only (1\%) had bone involvement, in agreement to $\mathrm{C} M$ Heaton et al. findings which were closely similar as only (4\%) of the patients had bone involvement [18].

On the topic of staging of the disease, this study showed that $(66.7 \%)$ of the patients were at stage IV, (18.8\%) were stage III, and only $(7.2 \%)$ were at stage II, in agreement to Henstrom D K et al. who found that $(80 \%)$ of the patients in his study had stage IV of the disease while only (5\%) had stage II [19], in contrast to Tallat Najeeb et al. who found in his study that (35.8\%) of the patients were at stage II of the disease while (5.5\%) of them were at stage I [11] and also G El-Husseiny et al. found that (61\%) of the patients in his study were at stage $\mathrm{T}(1-2)$ while only (36\%) were at stage $\mathrm{T}(3-4)$ [20]. Concerning the type of treatment that was done to patients in this study most of the patients underwent surgical treatment (52.2\%), (15.9\%) underwent adjuvant therapy and $(18.8 \%)$ of the patients having both, in agreement to Majeed Rana et al. who found that most of the patients in his study $(90 \%)$ underwent surgical treatment with only $(10 \%)$ of them underwent adjuvant therapy [21], in contrast to Andrew S Jones et al. who found that $(49.6 \%)$ of the patients in his study underwent adjuvant therapy and only $(24.8 \%)$ of them underwent surgical treatment [22]. About the treatment done to the patients in this study $(63 \%)$ undergone partial glossectomy, hemi glossectomy for(20.3\%) and total glossectomy for (8\%), in agreement with Anthony Po Wing Yuen et al. who found that (70.1\%) of patients in their study underwent partial glossectomy while only (15\%) of them underwent total glossectomy [23], in contrast to Nootan Kumar Shukla who found that (57.2\%) of the patient in their study underwent hemi glossectomy while (25.8\%) underwent partial glossectomy [17].

About bone resection in this study only (15.9\%) of the patient had undergone bone resection and (53.6\%) did not have bone resection, no previous studies discussed this parameter. Noteworthy, (34.8\%) of the patients had mandibulotomy and (29\%) did not, in agreement to Nootan Kumar Shukla et al. who had closely similar to ours, the authors found that $(61.3 \%)$ of their patients underwent mandibulotomy and (38.7\%) of them underwent trans-oral approach [17]. Regarding the type of surgical resection done to the patients in this study, (43.5\%) of them underwent segmental resection, (15.9\%) underwent soft tissue resection, and $(2.9 \%)$ of the patients underwent marginal resection. No previous studies discussed this parameter. About the surgical margins in this study, (37.7\%) were negative, (11.5\%) were positive, and only (1.4\%) were closed, in contrast to Nootan Kumar Shukla et al. who found in their study that (97.5\%) of the surgical margins were negative and only (2.4\%) were positive [18], also Snehal G et al. who found that (89\%) of the patients in his study had negative surgical margins and only (10\%) of them had positive surgical margins [24]. Concerning perineural invasion the authors found it in $(21.7 \%)$ of the patients in our study and $(65.2 \%)$ did not have a perineural invasion, in agreement to Amal Isaiah et al. whose findings were closely similar to ours in which they found that $(8.9 \%)$ of the patients in his study had perineural invasion and (91.1\%) did not [25], in contrast to Snehal G et al. who found that (85\%) of the patients in their study had perineural invasion with only (15\%) of them did not have it [24].

Regarding the lymphovascular invasion, we found it in (24.6\%) of the patients in this study and (62.3\%) were clear of it, in closely similar findings to Snehal G et al. as they found it in only (3\%) of the patients in his study with (97\%) of them not having it [24]. Concerning extranodal invasion (13\%) of the patients in our study experienced it while $(73.9 \%)$ did not have it, in similar findings to Nootan Kumar Shukla et al. who found that (26\%) of the patents in their study had extranodal invasion were the rest of them did not experience it [18], also Sohail Awan et al. found that (25.6\%) of the patients in their study had extranodal invasion while the rest of the patients were clear of it [26]. About the microscopic depth of invasion $(52.2 \%)$ of the patient in this study had a tumor that was $>$ or equal to $4 \mathrm{~mm}$ deep, $(10.1 \%)$ had a tumor that was $<4$ mm deep, and only (1.4\%) of the patients having a tumor that was $<4 \mathrm{~mm}$ deep, Snehal G et al. had closely similar findings to ours in that he found that (79\%) of the patients in his study had a tumor that was $>4 \mathrm{~mm}$ deep and only (21\%) of the patient's tumor was $<4 \mathrm{~mm}$ deep [24], in contrast to Amal Isaiah et al. who found that $(63.4 \%)$ of the patients in their study had $<3 \mathrm{~mm}$ deep tumor with only (35.7\%) of the patient having a >3 mm deep tumor [25].

Furthermore $(79.3 \%)$ of the patients in this study were found to have it while only (18.8\%) of them were clear of any pathologic lymph nodes, in closely similar findings to Nootan Kumar Shukla who found that $(56.4 \%)$ of the patients in his study had positive pathologic lymph nodes with the rest being clear of it [17], in contrast to Tao Zbang et al. who found that only (9.2\%) of the patients in his study had positive pathologic lymphnodes [27]. Concerning the adjuvant therapy (50.7\%) did not have any type of adjuvant therapy, $(21.7 \%)$ had radiotherapy and only $(1.4 \%)$ had chemotherapy, in agreement to Wenli Yang et al. who found that (68.5\%) of the patients in their study did not undergo adjuvant therapy with only (31.5\%) of them having to go through with it [28], in contrast to Nootan Kumar Shukla et al who found that (78.5\%) of the patients in their study had adjuvant therapy with the rest of them were not advised to have adjuvant therapy [17]. About the site of recurrence (44.9\%) of the patients in this study did not experience recurrence, (4.3\%) had local recurrence, and only (1.4\%) of the patients had locoregional recurrence, in closely similar findings to Nootan Kumar Shukla et al. who found that only (8.8\% and $10.4 \%$ ) of the patients in his study experienced local and regional recurrences respectively [17], in contrast to Jeffrey C et al. who found that $(63 \%)$ of the patients in his study experienced local recurrence [29]. Concerning the treatment for recurrence (4.3\% and $1.4 \%)$ of the patients in this study got treated with 


\section{Advances in Dentistry \& Oral Health}

surgery and radiotherapy respectively, in closely similar findings to Jeffrey $\mathrm{C}$ et al. who found that $(7.4 \%)$ of the patients in their study got treated with radiotherapy for the recurrence [25], in contrast to Amal Isaiah et al. who found that (50\%) of the patients in her study underwent surgical treatment for recurrence [25]. Regarding the mortality of the disease in this study (55\%) of the patients died while $(45 \%)$ of them are still alive, in contrast to Amal Isaiah et al. who found that the overall survival rate of the patients in their study was (89\%) [25], also Nootan Kumar Shukla et al. who found that the overall survival rate for the patients in their study was (78.6\%) [17].

In this study, we found that elderly patients more than 60 years old have a significantly low survival rate (P.value $=.000$ ), also over 60 patients present more frequently with pain (P.value $=.043$ ) and bone involvement tend to be more frequent in stage 4 (P.value $=.026)$. Negative margins and negative pathologic lymphnodes tend to be more frequent with partial glossectomy (P.value $=0.000$ and 0.001 respectively), also patients not taking any adjuvant therapy have better survival than those taking radiotherapy or chemotherapy or both (P. value $=.023$ ). Weakness points of this study include the decrease in sample size due to incomplete medical records.

\section{Conclusion}

Most of the patients diagnosed with oral tongue squamous cell carcinoma in this study were at a late stage (mainly stage IV) when they presented to the hospital. Ulcerative swelling was the most common clinical feature of the patients. Surgical treatment was the most common treatment done to the patients, most of the patients had negative surgical margins. Most of the patients did not have perineural invasion nor lymphovascular invasion, there was also no extranodal invasion in most of them, with the microscopic depth of invasion being more than $4 \mathrm{~mm}$ in most of them. Most of the patients did not experience any type of recurrence and the overall survival rate of the patients was $45 \%$

\section{References}

1. Krishnamurthy A, Ramshankar V (2013) Early stage oral tongue cancer among non-tobacco users--an increasing trend observed in a South Indian patient population presenting at a single centre. Asian Pac J Cancer Prev 14(9): 5061-5065.

2. Arrangoiz R, Cordera F, Caba D, Moreno E, de Leon EL, et al. (2018) Oral tongue cancer: Literature review and current management. Cancer Rep Rev 2(3).

3. Siegel RL, Miller KD, Jemal A (2018) Cancer statistics, CA: A Cancer Journal for Clinicians 68(1): 7-30

4. Hashibe M, Boffetta P, Zaridze D, Shangina O, Dabrowska NS, et al. (2006) Evidence for an important role of alcohol- and aldehydemetabolizing genes in cancers of the upper aerodigestive tract. Cancer Epidemiol Biomarkers Prev 15(4): 696-703.

5. Guha N, Boffetta P, Wünsch Filho V, Eluf Neto J, Shangina O, et al. (2007) Oral health and risk of squamous cell carcinoma of the head and neck and esophagus: results of two multicentric case-control studies. Am J Epidemiol 166(10): 1159-1173.
6. Barnes L, Eveson JW, Reichart P, Sidransky D (2005) World Health Organization Classification of Tumours. Pathology \& Genetics. Head and Neck Tumours. International Agency for Research on Cancer (IARC). WHO Classification of Tumours 3(9): 177-180

7. (2017) Alberta Health Services. Clinical practice guideline HN-006oral and dental care management in head and neck cancer.

8. Rusthoven KE, Raben D, Song JI, Kane M, Altoos TA, et al. (2010) Survival and patterns of relapse in patients with oral tongue cancer. J Oral Maxillofac Surg 68(3): 584-589.

9. D'Cruz AK, Sharma S, Agarwal JP, Thakar A, Teli A, et al. (2015) Indian Council of Medical Research consensus document for the management of tongue cancer. Indian J Med Paediatr Oncol 36(3): 140-145.

10. Tateda M, Shiga K, Saijo S, Yokoyama J (2000) A clinical study of oral tongue cancer. Tohoku J Exp Med 192(1): 49-59.

11. Najeeb T (2006) Clinicopathological presentation of tongue cancers and early cancer treatment. J Coll Physicians Surg Pak 16(3): 179-182.

12. Garavello W, Spreafico R, Somigliana E, Gaini L, Pignataro L, et al. (2008) Prognostic influence of gender in patients with oral tongue cancer. Otolaryngol Head Neck Surg 138(6): 768-771.

13. Sun W, Qiu Z, Tan W, Liu Z, Wang Z, et al. (2017) The influence of marital status on survival in patients with oral tongue squamous cell carcinoma. Oncotarget 8(47): 82092-82102.

14. Adeyemi BF, Akinyamoju AO, Kolude B (2018) Association of Squamous Cell Carcinoma of the Tongue with Cigarette and Alcohol Exposure: A Retrospective Clinicopathological Study. West Afr J Med 35(2): 117122

15. Bachar G, Hod R, Goldstein DP, Irish JC, Gullane PJ, et al. (2011) Outcome of oral tongue squamous cell carcinoma in patients with and without known risk factors. Oral Oncol 47(1): 45-50.

16. Yuen AP, Wei WI, Wong SH, Ng RW (1998) Local recurrence of carcinoma of the tongue after glossectomy: patient prognosis. Ear Nose Throat J 77(3): 181-184.

17. Shukla NK, Deo SVS, Garg PK, Manjunath NML, Bhaskar S, et al. (2018) Operable Oral Tongue Squamous Cell Cancer: 15 Years' Experience at a Tertiary Care Center in North India. Indian J Surg Oncol 9(1): 15-23.

18. Heaton CM, Al-Shwaiheen F, Liu CS, Yom SS, Ryan WR (2015) Prognostic significance of hyoid bone invasion in advanced base of tongue carcinoma treated by chemoradiation. Clin Otolaryngol 40(3): 260-265.

19. Henstrom DK, Moore EJ, Olsen KD, Kasperbauer JL, McGree ME (2009) Transoral resection for squamous cell carcinoma of the base of the tongue. Arch Otolaryngol Head Neck Surg 135(12): 1231-1238.

20. El-Husseiny G, Kandil A, Jamshed A, Khafaga Y, Saleem M, et al. (2000) Squamous cell carcinoma of the oral tongue: an analysis of prognostic factors. Br J Oral Maxillofac Surg 38(3): 193-139.

21. Kokemueller H, Rana M, Rublack J, Eckardt A, Tavassol F, et al. (2011) The Hannover experience: surgical treatment of tongue cancer--a clinical retrospective evaluation over a 30-year period. Head Neck Oncol 3: 27.

22. Jones AS, Rafferty M, Fenton JE, Jones TM, Husband DJ (2007) Treatment of squamous cell carcinoma of the tongue base: irradiation, surgery, or palliation? Ann Otol Rhinol Laryngol 116(2): 92-99.

23. Yuen AP, Wei WI, Wong SH, Ng RW (1998) Local recurrence of carcinoma of the tongue after glossectomy: patient prognosis. Ear Nose Throat J 77(3): 181-184.

24. Morris LG, Patel SG, Shah JP, Ganly I (2010) Squamous cell carcinoma of the oral tongue in the pediatric age group: a matched-pair analysis of survival. Arch Otolaryngol Head Neck Surg 136(7): 697-701. 
25. Ord RA, Isaiah A, Dyalram D, Lubek JE (2018) Is Long-Term FollowUp Mandatory for Stage I Oral Tongue Cancer? J Oral Maxillofac Surg 76(12): 2676-2683

26. Ahmed SQ Junaid M, Awan S, Kazi M, Khan HU, et al. (2018) Frequency of Cervical Nodal Metastasis in Early-Stage Squamous Cell Carcinoma of the Tongue. Int Arch Otorhinolaryngol 22(2): 136-140.

27. Zhang T, Lubek JE, Salama A, Dyalram D, Liu X, et al. (2014) Treatment of cT1N0M0 tongue cancer: outcome and prognostic parameters. J Oral Maxillofac Surg 72(2): 406-414.
28. Yang W, Sun M, Jie Q, Zhou H, Zhang P, et al. (2020) Lingual Lymph Node Metastasis in cT1-2N0 Tongue Squamous Cell Carcinoma: Is It an Indicator for Elective Neck Dissection. Front Oncol 10: 471.

29. Liu JC, Sopka DS, Mehra R, Lango MN, Fundakowski C, et al. (2016) Early oral tongue cancer initially managed with surgery alone: Treatment of recurrence. World J Otorhinolaryngol Head Neck Surg 2(4): 193-197.

\section{Your next submission with Juniper Publishers} will reach you the below assets

- Quality Editorial service

- Swift Peer Review

- Reprints availability

- E-prints Service

- Manuscript Podcast for convenient understanding

- Global attainment for your research

- Manuscript accessibility in different formats

( Pdf, E-pub, Full Text, Audio)

- Unceasing customer service

Track the below URL for one-step submission https://juniperpublishers.com/online-submission.php 